\title{
The Use of Health Functional Foods in Gastrointestinal Cancer Patients
}

\author{
Hwa Pyoung Kang ${ }^{1}$, Hosun Lee ${ }^{2}$, Tak Geun Oh${ }^{1}$, Kyong Joo Lee', Soo Jung Park', \\ Moon Jae Chung ${ }^{1 *}$, Seung Up Kim', Hyuk Lee', Jun Chul Park', Sung Pil Hong', \\ Jun Yong Park', Jeong Youp Park', Seungmin Bang', Do Young Kim', Jae Hee Cheon', \\ Sang Hoon Ahn', Tae II Kim', Seung Woo Park', Si Young Song' \\ 'Division of Gastroenterology, Yonsei Institute of Gastroenterology, Department of Internal \\ Medicine, Yonsei University College of Medicine, Seoul 245-905, Korea \\ ${ }^{2}$ Department of Nutrition and Dietetics, Severance Hospital, Seoul 120-752, Korea
}

\begin{abstract}
As an adjunct to cancer treatment, the use of health functional foods (HFFs) seems to be increasing. However, little is known for the use of HFFs among cancer patients in Korea. The aims of this study were to investigate the exposure rate of HFF use among gastrointestinal $(\mathrm{Gl})$ cancer patients and to examine the relationship of socio-demographic and disease-related characteristics with the use of HFFs. A total of 126 patients diagnosed with $\mathrm{Gl}$ cancer participated in the study. A cross-sectional survey was conducted using a questionnaire. Over a half of all the patients surveyed $(n=67 ; 53.2 \%)$ used HFFs. Patients who were younger, had higher income, or longer duration of disease showed a trend to use HFFs more frequently, even though the tendency was not statistically significant. The most commonly used HFF was vitamin complex $(n=20 ; 16 \%)$, followed by red ginseng $(n=15 ; 12 \%)$, and sweet wormwood (Artemisia annua) $(n=11 ; 8.8 \%)$. About $26 \%$ of all responders expressed concerns for using HFFs. The primary concern was 'going against physician's recommendations' (36.8\%). About $63 \%$ of respondents expressed a desire to consult with their physicians and follow their recommendations. More basic scientific data and educational materials regarding HFFs are required for both health-care professionals and cancer patients. A larger sample and size-controlled groups representing each cancer type will continue to be recruited for participation in this survey.
\end{abstract}

Key Words: Health functional food, Gastrointestinal cancer

*Corresponding author Moon Jae Chung

Address Division of Gastroenterology, Yonsei Institute of Gastroenterology, Department of Internal Medicine, Yonsei University College of Medicine, 50 Yonsei-ro, Seodaemun-gu, Seoul 120-752, Korea Tel +82-2-2228-1981 Fax +82-2-2228-1981

E-mail mjchung@yuhs.ac

Received December 5, 2012

Revised December 15, 2012

Accepted December 20, 2012

\section{(C) 2013 The Korean Society of Clinical Nutrition}

This is an Open Access article distributed under the terms of the Creative Commons Attribution Non-Commercial License (http://creativecommons.org/licenses/by-nc/3.0/) which permits unrestricted non-commercial use, distribution, and reproduction in any medium, provided the original work is properly cited.

\section{Introduction}

In the field of cancer treatment, complementary and alternative medicine (CAM) is used as an adjunct therapy to conventional medicine. Uses of CAM in cancer patients is aimed to relieve or prevent cancer-related symptoms [1], to treat cancer itself (similar to chemotherapy and radiotherapy) [2], and to impart a patient sense of active involvement in cancer treatment [3]. Despite insufficient scientific evidence, the use of CAM is increasing worldwide, and up to $80 \%$ of cancer patients are reported to use it [4]. In Korea, a multicenter study reported that more than 50\% of cancer patients utilized CAM. In contrast with Western countries, dietary supplements, such as health functional foods (HFFs), are the most widely used 
among the various types of CAM in Korea [5].

As interest in the use of the HFFs increase in cancer patients, safety concerns about these treatments are also increasing [6]. Most individuals believe that HFFs are not harmful because they were made from natural materials [7]. However, some HFFs have been reported to produce serious side effects, such as hepatic and renal failure, cause harmful interactions with prescription drugs, and reduce the efficacy of other drugs $[8,9]$. Particularly, in the case of natural foods not approved by the Korean Food and Drug Administration (KFDA), food safety might be problematic. Considering these potential problems, cancer patients should receive counsel from health care professionals regarding the use of HFFs, although most of them do not $[10,11]$.

As an adjunct to cancer treatment, the use of HFFs seems to be increasing. However, little is known about the use of HFFs among cancer patients in Korea. It is essential to determine the exposure rate of HFFs and factors influencing preferences for HFFs used among cancer patients. The aims of this study were to investigate the exposure rate of HFFs used among gastrointestinal (GI) cancer patients and to examine any relationships between socio-demographics and disease-related characteristics with HFFs used.

\section{Materials and Methods}

Study design and subjects

This was a cross-sectional survey using a questionnaire distributed and collected by hospital personnel to GI cancer patients who visited the out-patient department or were admitted to Severance Hospital. All enrolled patients were followedup at the Department of Gastroenterology, were greater than 20 years of age and had been radiologically or histologically diagnosed with $\mathrm{Gl}$ cancer. Between November $4^{\text {th }}, 2012$ and November $24^{\text {th }}, 2012,126$ patients (79 male, 47 female) were enrolled. The study protocol and questionnaire were approved by the Institutional Review Board of Severance Hospital, and written informed consent was obtained from each patient before enrollment.

\section{Survey}

Based on a previous study [12], the contents of the questionnaire were prepared by a clinical dietitian and several medical doctors who collaborated on this study. The questionnaire included four questions on socio-demographic characteristics (gender, age, educational status, average income per month), three questions on disease-related characteristics (site of cancer, date of diagnosis, and current cancer treatment), a number of questions related to HFF use (type of HFFs, duration of use, cost, route of obtainment, reason for use) and three questions on patient response to HFF use (recognizable changes after use, concerns related to HFFs, plan about further use). There was a list of HFFs that subjects could select. Participants were able to choose multiple items that they had used more than once since their cancer diagnosis. We referred to the KFDA website [13] in order to compose the HFF list and also included some folk remedies which are known to be widely used in Korea. At the end of the list, there were free-text boxes for respondents to add any HFFs, or folk remedies which were not included in the pre-coded list.

\section{Data analysis and statistical methods}

Binary logistic regression and Chi-squared tests were used to analyze the socio-demographic and disease-related factors predicting HFF use. A p-value less than 0.05 was considered to indicate statistical significance. All data analyses were performed using SPSS (version 18.0, SPSS Inc., Chicago, IL, USA).

\section{Results}

\section{Patient characteristics and HFF use}

Table 1 shows participants' socio-demographic characteristics and disease-related characteristics. The majority of participants were male $(n=79 ; 62.7 \%)$ and between 61 and 70 years of age $(n=53 ; 42 \%)$. High school was the highest level of education of most respondents ( $n=50 ; 42.7 \%$ ). Thirty-four percent of patients earned between 1 and 3 million Korean won (KRW) per month, which accounted for the largest group of patients (34.2\%). With regard to disease-related characteristics, pancreatobiliary cancer was the most common cancer among the enrolled patients ( $n=72 ; 56.7 \%$ ). Fifty-seven patients (45.2\%) had been diagnosed for less than 6 months. Ninety-one patients (72.2\%) were undergoing chemotherapy at the time of the survey, and 22 patients (17.5\%) were undergoing radiotherapy.

Over half of all the patients ( $n=67 ; 53.2 \%$ ) used HFFs (Table 1). The relationship between HFF use and participants' characteristics was analyzed, and it was shown that the same proportion of male and female participants used HFFs ( $n=42$; $53.2 \%$ vs. $n=25 ; 53.2 \%$ ). None of the characteristics showed 


\section{Use of Health Functional Foods in Gastrointestinal Cancer Patients}

Table 1. Characteristics of the participants

\begin{tabular}{|c|c|c|c|}
\hline Characteristic & Participant no. (\%) & HFF users (\%) & Bivariate OR $(95 \% \mathrm{CI})$; significance \\
\hline \multicolumn{4}{|l|}{ Gender } \\
\hline Male & 79 (62.7) & $42(53.2)$ & $1.0(0.5-2.0) ; 0.998$ \\
\hline Female & $47(37.3)$ & $25(53.2)$ & Reference \\
\hline \multicolumn{4}{|l|}{ Age, yr } \\
\hline$<61$ & 47 (37.3) & 27 (57.4) & $1.6(0.6-4.1) ; 0.356$ \\
\hline $61-70$ & $53(42)$ & 28 (52.8) & $1.3(0.5-3.3) ; 0.577$ \\
\hline$\geq 71$ & $26(20.6)$ & $12(46.2)$ & Reference \\
\hline \multicolumn{4}{|c|}{ Highest level of education* } \\
\hline Elementary school & $15(12.8)$ & $9(60.0)$ & $1.5(0.4-5.4) ; 0.537$ \\
\hline Middle school & $26(22.2)$ & $11(42.3)$ & $0.7(0.2-2.2) ; 0.578$ \\
\hline High school & $50(42.7)$ & $29(58.0)$ & $1.4(0.5-3.6) ; 0.506$ \\
\hline College / University & $26(22.2)$ & $13(50.0)$ & Reference \\
\hline \multicolumn{4}{|c|}{ Average income per month $(10,000 \mathrm{KRW})^{+}$} \\
\hline$<100$ & $37(32.5)$ & $18(48.6)$ & $0.5(0-5.7) ; 0.556$ \\
\hline $100-300$ & $39(34.2)$ & $22(56.4)$ & $0.6(0.1-7.7) ; 0.731$ \\
\hline $300-500$ & 31 (27.2) & $16(51.6)$ & $0.5(0-6.5) ; 0.622$ \\
\hline $500-1000$ & $4(3.5)$ & $3(75.0)$ & $1.5(0.1-40.6) ; 0.810$ \\
\hline$>1000$ & $3(2.6)$ & $2(66.7)$ & Reference \\
\hline \multicolumn{4}{|l|}{ Cancer type $^{*}$} \\
\hline Stomach & $8(6.3)$ & $5(62.5)$ & $3.3(0.4-30.7) ; 0.288$ \\
\hline Pancreatobiliary & 72 (56.7) & $36(50.0)$ & $2.0(0.3-11.6) ; 0.440$ \\
\hline Liver & $25(19.7)$ & $14(56.0)$ & $2.8(0.4-18.4) ; 0.283$ \\
\hline Colorectal & $16(12.6)$ & $10(62.5)$ & $3.3(0.5-24.0) ; 0.232$ \\
\hline Others ${ }^{\S}$ & $6(4.7)$ & $2(33.3)$ & Reference \\
\hline \multicolumn{4}{|l|}{ Months since diagnosis } \\
\hline$<6$ & $57(45.2)$ & $26(45.6)$ & $0.5(0.3-1.3) ; 0.200$ \\
\hline $6-12$ & $30(23.8)$ & $18(60.0)$ & $1.0(0.4-2.8) ; 0.931$ \\
\hline$>12$ & $39(31)$ & $23(59.0)$ & Reference \\
\hline \multicolumn{4}{|l|}{ Current chemotherapy } \\
\hline Yes & 91 (72.2) & $48 \quad(52.7)$ & $0.9(0.4-2.1) ; 0.877$ \\
\hline No & 35 (27.8) & $19(54.3)$ & Reference \\
\hline \multicolumn{4}{|l|}{ Current radiotherapy } \\
\hline Yes & $22(17.5)$ & $13(59.1)$ & $1.3(0.5-3.4) ; 0.541$ \\
\hline No & $104(82.5)$ & $54(51.9)$ & Reference \\
\hline All participants & $126(100)$ & $67(53.2)$ & \\
\hline
\end{tabular}

HFFs: health functional foods, OR: odds ratio, Cl: confidence interval, KRW: Korean won.

${ }^{*}$ Nine participants did not answer the question about their highest level of education- odds ratio computed for 117 participants only; ${ }^{\dagger}$ There were 12 nonresponses on the question about average income per month - odds ratio calculated for only 114 participants; ${ }^{\dagger}$ One participant had double primary cancer (stomach cancer and hepatocellular carcinoma); ${ }^{\text {T}}$ These include four ampulla of Vater cancers and one gastrointestinal stromal tumor (GIST).

a statistically significant difference in HFF use on bivariate analysis. According to age, average monthly income, and length of time since diagnosis, patients who were younger, had a higher income or a longer duration of disease trended to 


\section{Kang HP et al.}

use HFFs more frequently, but the difference was not statistically significant. Because of these results, none of the characteristics could be included in multivariate analysis. Therefore, it was not possible to calculate the multivariate odds ratio.

\section{Types of specific HFF used}

Every HFF used by participants at least once was included in the analysis and is shown in Table 2. The most commonly used HFF was vitamin complex $(n=20 ; 16 \%)$, followed by red ginseng ( $n=15 ; 12 \%)$, sweet wormwood (Artemisia annua) $(n=11 ; 8.8 \%)$, vitamin $C(n=8 ; 6.4 \%)$ and chaga mushroom (Inonotus obliquus) $(n=8 ; 6.4 \%)$, with sweet wormwood and chaga mushroom being natural foods and the others being dietary ingredients approved by the KFDA as dietary supplements.

\section{Route of obtainment and concerns about HFF use}

Forty-four percent of patients who use HFFs obtained these materials as a gift $(n=30 ; 44.1 \%)$ (Table 3$)$. Other patients obtained HFFs from a health food store or grocery store $(n=20$; 29.4\%). The expectation of a synergistic effect in combination with conventional cancer therapy was the most common reason for using HFFs ( $n=33 ; 40.7 \%)$, followed by recommendation from family members, friends, or other cancer patients ( $\mathrm{n}$ $=23 ; 28.4 \%)$. In terms of recognizable change after use, 42.6 $\%$ of patients thought nothing changed after using HFFs (n $=29$ ). Seventeen patients $(26.6 \%)$ expressed concerns about using HFF, as it was against their physician's recommendations $(n=7 ; 36.8 \%)$, and lack of scientific evidence about the efficacy and safety of HFFS was another concern of patients ( $\mathrm{n}$ $=4 ; 21.1 \%)$. As to the question of further use of HFFs, $63.3 \%$ of patients planned to consult with their physician about the issue and follow their doctor's recommendation $(n=38)$, and $33.3 \%$ planned to continue to use HFFs $(n=20)$.

\section{Discussion}

Fifty-three percent of Gl cancer patients enrolled in this study used HFFs at the time of the survey. This is a higher percentage than that in a report from Western countries (16.8\%) [14] but lower than data from a previous study conducted in Korea (78.1\%) [15]. There were no significant differences in the use of HFFs according to socio-demographic or diseaserelated factors. Even though it was not statistically significant, patients who were younger, had a higher income, or a longer duration of cancer tended to more commonly use HFFs. A previous study revealed that HFF users tend to be younger (less than 50 years of age), female patients with a higher socioeconomic status and a longer duration of disease [14], whereas another study showed no differences between HFFs users and non-users according to patient characteristics [15]. Several Korean studies have shown that younger cancer patients are more likely to use HFFs [16-18].

The most commonly used HFF was vitamin complex, followed by red ginseng and sweet wormwood (Artemisia annua). As in a previous study $[15,19]$, frequently used HFFs in this survey could be categorized as 'Vitamins/Minerals' (i.e., vitamin complex, vitamin C and calcium) and 'Natural materials' (i.e., mushrooms, vegetables and herbs).

The pancreatobiliary cancer group seemed to use various types of HFFs listed in this study. However, there was no statistical evidence regarding which specific kinds of HFFs $\mathrm{Gl}$ cancer patients choose according to their cancer site. In terms of the site of cancer, the pancreatobiliary cancer group comprised the majority of participants (56.7\%), which is different from previously reported cancer studies in Korea [20]. This may be the result of the short enrollment period and the relatively small sample size. As such, participants in this study are not representative of all cancer patients in Korea. Despite these limitations, this study still has some value as a preliminary study.

In terms of the reason for use of HFFs, the majority of participants expected some synergistic effect between their traditional cancer treatment and the use of HHFs or had started using HFFs based on a recommendation from family members or acquaintances. After using HFFs, $42.6 \%$ of users experienced no subjective changes, whereas 23.5\% and 20.6\% felt less anxious and less tired about their cancer. However, there is still little scientific evidence to support such claims. Approximately one-quarter of all responders worried about using HFFs. A major concern was 'going against physician's recommendations,' especially given that $63.3 \%$ of respondents wanted to consult with their physicians and follow their recommendations. However, health-care professionals tend to devalue HFF usage [15], which leads to cancer patients rarely consulting with health-care professionals about the issue [21]. Thus, openness and a flexible attitude toward HFFs and more interest in education about HFF use is needed for health-care professionals who work with cancer patients.

Overall, more than $50 \%$ of $\mathrm{Gl}$ cancer patients reported having used HFFs, and the exposure rate to HFFs is anticipated to 


\section{Use of Health Functional Foods in Gastrointestinal Cancer Patients}

Table 2. Frequencies of use for specific HFFs and use by cancer type

\begin{tabular}{|c|c|c|c|c|c|c|}
\hline \multirow{2}{*}{ Name (scientific name) } & \multirow{2}{*}{$\begin{array}{l}\text { Number of } \\
\text { users (\%) }\end{array}$} & \multicolumn{5}{|c|}{ Number of users by cancer site (\%)* } \\
\hline & & Stomach & Pancreatobiliary & Liver & Colorectal & Other cancers ${ }^{\dagger}$ \\
\hline \multicolumn{7}{|l|}{ HFFs approved by KFDA } \\
\hline Aloe (Aloe arborescens Mill) & $1(0.8)$ & - & - & $1(100.0)$ & - & - \\
\hline Black mushroom (Lentinula edodes) & $1(0.8)$ & - & $1(100.0)$ & - & - & - \\
\hline Calcium & $1(0.8)$ & - & - & - & $1(100.0)$ & - \\
\hline Dietary fiber & $1(0.8)$ & - & - & - & $1(100.0)$ & - \\
\hline Enzyme foods & $6(4.8)$ & - & $6(100.0)$ & - & - & - \\
\hline Fermented soy-bean powder & $1(0.8)$ & - & $1(100.0)$ & - & - & - \\
\hline Ginseng & $2(1.6)$ & - & - & - & $1(50.0)$ & $1(50.0)$ \\
\hline Glucosamine & $4(3.2)$ & - & $3(75.0)$ & - & $1(25.0)$ & - \\
\hline Iron supplement & $1(0.8)$ & $1(100.0)$ & - & - & - & - \\
\hline Omega-3 & $4(3.2)$ & - & $2(50.0)$ & $1(25.0)$ & $1(25.0)$ & - \\
\hline Onion extract & $2(1.6)$ & - & $1(50.0)$ & $1(50.0)$ & - & - \\
\hline Oriental raisin tree fruit (Hovenia dulcis) & $4(3.2)$ & - & $1(25.0)$ & $3(75.0)$ & - & - \\
\hline Red ginseng & $15(12)$ & $1(6.7)$ & $6(40.0)$ & $4(26.7)$ & $3(20.0)$ & $1(6.7)$ \\
\hline Reishi mushroom (Ganoderma lucidum) & $2(1.6)$ & - & $1(50.0)$ & - & $1(50.0)$ & - \\
\hline Sangwhang mushroom (Phellinus Linteus) & $3(2.4)$ & - & - & - & $3(100.0)$ & - \\
\hline Vegetable worms (Cordyceps militaris) & $1(0.8)$ & - & - & - & - & $1(100.0)$ \\
\hline Vitamin C & $8(6.4)$ & - & $4(50.0)$ & - & $4(50.0)$ & - \\
\hline Vitamin complex & $20(16)$ & $1(5.0)$ & $9(45.0)$ & $4(20.0)$ & $4(20.0)$ & $2(10.0)$ \\
\hline \multicolumn{7}{|l|}{ Natural food not approved by KFDA } \\
\hline Black garlic extract & $4(3.2)$ & - & $2(50.0)$ & $2(50.0)$ & - & - \\
\hline Capillary wormwood (Artemisia capillaris) & $1(0.8)$ & - & $1(100.0)$ & - & - & - \\
\hline Chaga mushroom (Inonotus obliquus) & $8(6.4)$ & $1(12.5)$ & $5(62.5)$ & $1(12.5)$ & $1(12.5)$ & - \\
\hline Chinese osage orange (Cudrania tricuspidata) & $1(0.8)$ & - & $1(100.0)$ & - & - & - \\
\hline Colostrums powder & $1(0.8)$ & - & - & $1(100.0)$ & - & - \\
\hline Dandelion (Taraxacum platycarpum Dahlst) & $4(3.2)$ & - & $2(50.0)$ & $1(25.0)$ & $1(25.0)$ & - \\
\hline Fresh grinded dry meal & $1(0.8)$ & - & $1(100.0)$ & - & - & - \\
\hline Green vegetable juice & $3(2.4)$ & - & $1(33.3)$ & $1(33.3)$ & $1(33.3)$ & - \\
\hline Hooker chives (Allium hookeri) & $1(0.8)$ & - & $1(100.0)$ & - & - & - \\
\hline Japanese elm (Ulmus davidiana var. japonica) & $2(1.6)$ & - & $2(100.0)$ & - & - & - \\
\hline Mistletoe (Viscum album) & $4(3.2)$ & - & $2(50.0)$ & - & $2(50.0)$ & - \\
\hline Orostachys japonicus water extracts & $2(1.6)$ & - & $2(100.0)$ & - & - & - \\
\hline Spotted spurge (Ceramium kondoi) & $1(0.8)$ & - & $1(100.0)$ & - & - & - \\
\hline Sweet wormwood (Artemisia annua) & $11(8.8)$ & - & $8(72.7)$ & $1(9.1)$ & $1(9.1)$ & $1(9.1)$ \\
\hline Vegetable decoction & $4(3.2)$ & $1(25.0)$ & $3(75.0)$ & - & - & - \\
\hline Any HFFs \& HSFs & 125 & $5(4.0)$ & $67(53.6)$ & $21(16.8)$ & $26(20.8)$ & $6(4.8)$ \\
\hline
\end{tabular}

KFDA: Korea Food and Drug Administration, HFFs: health functional foods, HSFs: health supplementary foods.

*Percentages refer to the proportion of users of each HFF from within each cancer type; ${ }^{\top}$ These include four ampulla of Vater cancers and one gastrointestinal stromal tumor (GIST). 
Table 3. Questions about HFF use and patient stance on their use

\begin{tabular}{|c|c|}
\hline Questions* & Number (\%) \\
\hline \multicolumn{2}{|l|}{ Route of obtainment } \\
\hline Bought directly at a health food store, mall, or grocery store & $20(29.4)$ \\
\hline From someone as a gift & $30(44.1)$ \\
\hline Through mail order or on the internet & $6(8.8)$ \\
\hline Prescription by hospital doctor & $8(11.8)$ \\
\hline Others $^{+}$ & $4(5.9)$ \\
\hline \multicolumn{2}{|l|}{ Reason for use } \\
\hline Expectation of synergistic effect in combination with conventional cancer therapy & $33(40.7)$ \\
\hline Recommendation from family members, friends, or other cancer patients & $23(28.4)$ \\
\hline Already had started taking HFFs before the diagnosis was made & $10(12.3)$ \\
\hline Information from TV, magazine, newspaper or internet news & $7(8.6)$ \\
\hline Information from internet community related to cancer treatment & $4(4.9)$ \\
\hline To eliminate anxiety about cancer itself & $1(1.2)$ \\
\hline Others ${ }^{\dagger}$ & $3(3.7)$ \\
\hline \multicolumn{2}{|l|}{ Recognizable changes after use } \\
\hline Cancer-related symptoms are relieved & $7(10.3)$ \\
\hline Feel better and less tired & $14(20.6)$ \\
\hline Anxiety about cancer is decreased & $16(23.5)$ \\
\hline Nothing changed significantly & $29(42.6)$ \\
\hline Others ${ }^{\S}$ & $2(2.9)$ \\
\hline Presence of concerns related to HFFs & $17(26.6)$ \\
\hline Lack of scientific evidence about efficacy and safety & $4(21.1)$ \\
\hline Going against my physician's recommendation & $7(36.8)$ \\
\hline Delay of conventional cancer treatment due to adverse effect of HFFs & $1(5.3)$ \\
\hline Experience of symptoms related to adverse effect of HFFs & $3(15.8)$ \\
\hline Cost & $4(21.1)$ \\
\hline Others & $0(0)$ \\
\hline \multicolumn{2}{|l|}{ Plan about further use } \\
\hline Continue to use & $20(33.3)$ \\
\hline Stop taking HFFs & $0(0)$ \\
\hline Consult with my physician and follow the recommendation & $38(63.3)$ \\
\hline Others" & $2(3.3)$ \\
\hline
\end{tabular}

HFFs: health functional foods.

*Each question allowed participants to choose multiple responses: 'This includes three 'I made it myself from natural materials' and one 'Offered free at nursing home' responses; ; Includes options of 'Doctor's recommendation,' 'To control the treatment-related symptoms' and 'no response'; 'Includes 'Suffered discomfort symptoms' and 'no response'; "Includes 'Confused.'

grow. Patients who were younger, had a higher income, or had a longer cancer duration tended to more commonly use HFFs. More basic scientific data and educational materials are required for both health-care professionals and cancer patients. A larger sample and size-controlled groups representing each cancer type will continue to be recruited for participation in this survey. 


\section{Use of Health Functional Foods in Gastrointestinal Cancer Patients}

\section{References}

1. Ali N, Hussain-Gambles M. Complementary and alternative medicine (CAM) use among South Asian patients with cancer in Britain. Divers Health Soc Care 2005;2:41-6.

2. Vickers KA, Jolly KB, Greenfield SM. Herbal medicine: women's views, knowledge and interaction with doctors: a qualitative study. BMC Complement Altern Med 2006;6:40.

3. Verhoef MJ, Hilsden RJ, O'Beirne M. Complementary therapies and cancer care: an overview. Patient Educ Couns 1999;38:93-100.

4. Cassileth BR, Deng G. Complementary and alternative therapies for cancer. Oncologist 2004;9:80-9.

5. Lee E, Shin YC, Lee J, Kim SD, Kim HJ, Jo MS. Use of complementary and alternative medicine in cancer patients at 7 general hospitals in Seoul. J Korean Public Health Assoc 2002;28:225-38.

6. Balneaves LG, Kristjanson LJ, Tataryn D. Beyond convention: describing complementary therapy use by women living with breast cancer. Patient Educ Couns 1999;38:143-53.

7. Cassileth $B_{1}$ Heitzer M, Gubili J. Integrative oncology: complementary therapies in cancer care. Cancer Chemother Rev 2008;3:204-11.

8. Frye RF, Fitzgerald SM, Lagattuta TF, Hruska MW, Egorin MJ. Effect of St John's wort on imatinib mesylate pharmacokinetics. Clin Pharmacol Ther 2004;76:323-9.

9. Cassileth B, Yeung KS, Gubili J. Herbs and other botanicals in cancer patient care. Curr Treat Options Oncol 2008;9:109-16.

10. Wang $\mathrm{S}$. A research on the actual use of complementary and alternative therapies by cancer patients. Seoul: Kyung Hee University; 2007.

11. Moon HW. A study on the use of the complementary and alternative therapy in female cancer patients. Korean J Womens Health 2004;5:1944.

12. Gratus $C$, Damery $S$, Wilson $S$, Warmington $S$, Routledge $P$, Grieve $R$, Steven N, Jones J, Greenfield $S$. The use of herbal medicines by people with cancer in the UK: a systematic review of the literature. QJM 2009;102:831-42.

13. Korea Food \& Drug Administration. Health functional food categorized by raw materials. Available from http://www.foodnara.go.kr/hfoodi/ [cited 2012 October 5]. 2009.

14. Damery S, Gratus C, Grieve R, Warmington S, Jones J, Routledge P, Greenfield S, Dowswell G, Sherriff J, Wilson S. The use of herbal medicines by people with cancer: a cross-sectional survey. $\mathrm{Br} J$ Cancer 2011;104:927-33.

15. Kim IK. The use of the functional foods in elderly patients with digestive system cancers. J Korean Gerontol Nurs 2010;12:51-61.

16. Song HW. Complementary alternative medicine use of the admitted cancer patients to a general hospital. Health Welf 2004;7:37-60.

17. Seol KL, Choi SY, Lee Jl. A study on the use, understanding and satisfaction with alternative therapy for hospitalized cancer patients. J Korean Public Health Assoc 2002;28:198-211.

18. Kim MJ, Lee SD, Kim DR, Kong YH, Sohn WS, Ki SS, Kim J, Kim YC, Han CJ, Lee JO, Nam HS, Park YH, Kim CH, Yi KH, Lee YY, Jeong SH. Use of complementary and alternative medicine among Korean cancer patients. Korean J Intern Med 2004;19:250-6.

19. Qiao $Y L$, Dawsey $S M$, Kamangar $F$, Fan JH, Abnet $C C$, Sun $X D$, Johnson LL, Gail MH, Dong ZW, Yu B, Mark SD, Taylor PR. Total and cancer mortality after supplementation with vitamins and minerals: followup of the Linxian General Population Nutrition Intervention Trial. J Natl Cancer Inst 2009;101:507-18.

20. Ministry of Health \& Welfare. Cancer facts \& figures 2012 in the Republic of Korea. Seoul: Ministry of Health \& Welfare; 2012.

21. Corner J, Harewood J, Maslin-Prothero S, Lewith G. A study of the use of complementary and alternative therapies among people undergoing cancer treatment: a quantitative and qualitative study. Department of Health NHS R\&D programme. London: Department of Health; 2006. 